\title{
Cardiorespiratory fitness attenuates age- associated aggregation of white matter hyperintensities in an at-risk cohort
}

\author{
Clayton J. Vesperman ${ }^{1,2}$ (D) Vincent Pozorski ${ }^{1,5}$, Ryan J. Dougherty ${ }^{2,4}$, Lena L. Law ${ }^{1,2}$, Elizabeth Boots ${ }^{8,9}$, \\ Jennifer M. Oh ${ }^{1,2}$, Catherine L. Gallagher ${ }^{1,2,5}$, Cynthia M. Carlsson 1,2,3 ${ }^{1, H o w a r d ~ A . ~ R o w l e y ~}{ }^{2,7}$, Yue Ma', \\ Barbara B. Bendlin ${ }^{1,2,3}$, Sanjay Asthana ${ }^{1,2}$, Mark A. Sager ${ }^{2,3}$, Bruce P. Hermann ${ }^{2,3,5}$, Sterling C. Johnson ${ }^{1,2,3}$, \\ Dane B. Cook ${ }^{4,6}$ and Ozioma C. Okonkwo 1,2,3,10*
}

\begin{abstract}
Background: Age is the cardinal risk factor for Alzheimer's disease (AD), and white matter hyperintensities (WMH), which are more prevalent with increasing age, may contribute to AD. Higher cardiorespiratory fitness (CRF) has been shown to be associated with cognitive health and decreased burden of AD-related brain alterations in older adults. Accordingly, the aim of this study was to determine whether CRF attenuates age-related accumulation of WMH in middle-aged adults at risk for AD.

Methods: One hundred and seven cognitively unimpaired, late-middle-aged adults from the Wisconsin Registry for Alzheimer's Prevention underwent $3 \mathrm{~T}$ magnetic resonance imaging and performed graded maximal treadmill exercise testing from which we calculated the oxygen uptake efficiency slope (OUES) as our measure of CRF. Total WMH were quantified using the Lesion Segmentation Tool and scaled to intracranial volume. Linear regression adjusted for APOE4 carriage, family history, body mass index, systolic blood pressure, and sex was used to examine relationships between age, $\mathrm{WMH}$, and CRF.
\end{abstract}

Results: As expected, there was a significant association between age and WMH $(p<.001)$. Importantly, there was a significant interaction between age and OUES on WMH ( $p=.015)$. Simple main effects analyses revealed that the effect of age on WMH remained significant in the Low OUES group $(p<.001)$ but not in the High OUES group $(p=.540)$, indicating that higher CRF attenuates the deleterious age association with WMH.

Conclusions: Higher CRF tempers the adverse effect of age on WMH. This suggests a potential pathway through which increased aerobic fitness facilitates healthy brain aging, especially among individuals at risk for AD.

Keywords: Alzheimer's disease, White matter hyperintensities, Cardiorespiratory fitness

\section{Background}

With the aging population, the number of people with Alzheimer's disease (AD) in the United States is projected to reach 13.8 million people by 2050 , in the absence of preventative or curative therapies [1]. White matter hyperintensities (WMH), commonly observed in

\footnotetext{
* Correspondence: ozioma@medicine.wisc.edu

${ }^{1}$ Geriatric Research Education and Clinical Center, William S. Middleton

Memorial Veterans Hospital, Madison, WI 53705, USA

'Wisconsin Alzheimer's Disease Research Center, University of Wisconsin

School of Medicine and Public Health, Madison, WI 53792, USA

Full list of author information is available at the end of the article
}

older adults, are characterized by bright areas on magnetic resonance imaging (MRI) using T2-weighted or T2 fluid-attenuated inversion recovery (FLAIR) sequences $[16,47]$. WMH have been shown to predict AD earlier in life, and may be the "second hit" required to progress a person to clinical $\mathrm{AD}[8,16,33,40]$. Indeed, $\mathrm{WMH}$ are now considered by some to be a core component of AD pathophysiology, and/or caused by chronic ischemia associated with cerebral small vessel disease $[9,33]$. The factors that most contribute to the development of WMH are aging and cardiovascular disease [34, 39, 49].

(c) The Author(s). 2018 Open Access This article is distributed under the terms of the Creative Commons Attribution 4.0 International License (http://creativecommons.org/licenses/by/4.0/), which permits unrestricted use, distribution, and 
Cardiorespiratory fitness (CRF), an index of habitual physical activity, has been associated with preserved cognitive function and brain structure in older adults $[10,20,21,25,27,38]$. It has also been associated with a lower risk of dementia in the elderly [14, 18, 46]. Interestingly, individuals with higher CRF have also been shown to have lower WMH $[7,13,37]$. This association may indicate that by leading a physically active lifestyle, an individual might slow their accumulation of WMH as they age, and thus enjoy healthier brain aging.

Although peak oxygen consumption $\left(\mathrm{VO}_{2}\right.$ peak $)$ is traditionally regarded as the gold standard measure for CRF [2], older adults as a whole are known to struggle with meeting the criteria for peak effort during maximal graded exercise testing (GXT). The oxygen uptake efficiency slope (OUES) was developed as an effort-independent measure of CRF that is nonetheless highly correlated with $\mathrm{VO}_{2}$ peak $[3,24]$. Accordingly, the OUES served as our index of CRF in this study, which examined associations between CRF, age, and WMH [19]. We hypothesized that older age would be associated with more WMH, but that higher CRF would attenuate this deleterious effect of aging on WMH.

\section{Methods}

\section{Participants}

We utilized data provided by 107 participants enrolled in an ancillary study-Fitness, Aging, and the Brain-of the Wisconsin Registry for Alzheimer's Prevention (WRAP). WRAP is a longitudinal study consisting of approximately 1500 , late-middle-aged adults who were free of dementia and were between the ages of 40 and 65 years at study entry [28]. The cohort is enriched with risk factors for AD including positive family history for $\mathrm{AD}(\mathrm{FH})$ and/or apolipoprotein E $\varepsilon 4$ allele (APOE4) carriage [28, 32, 42]. Participants were enrolled in the ancillary study if they were determined to have no MRI contraindications and could perform a GXT safely. The mean amount of time between the MRI and GXT was $1.04 \pm 1.04$ years. All study procedures were approved by the University of Wisconsin Institutional Review Board and each participant provided informed consent prior to participation.

\section{Graded exercise testing}

GXT was performed using a modified Balke protocol [4]. A comfortable, yet quick, walking speed was determined for each participant before testing, as a safety measure. For those able to, a walking speed of 3.5 miles per hour was used throughout the test. Every $2 \mathrm{~min}$, the incline of the treadmill was increased by $2.5 \%$ until the participant reached volitional exhaustion. Oxygen uptake $\left(\mathrm{VO}_{2}\right)$, carbon dioxide production, minute ventilation (VE), heart rate, and work rate were measured continuously using a metabolic cart and two-way nonrebreathing valve (TrueOne ${ }^{ø}$ 2400; Parvomedics, Sandy, UT, USA). The
OUES was determined for each participant by calculating the regression slope from the linear relationship of absolute $\mathrm{VsO}_{2}\left(\mathrm{ml} \cdot \mathrm{min}^{-1}\right)$ plotted as a function of $\log _{10} \mathrm{VE}\left(\mathrm{ml} \cdot \mathrm{min}^{-1}\right)$ (i.e., $\left.\mathrm{VO}_{2}=a \log _{10} \mathrm{VE}+b\right)$ [3]. The OUES values were then adjusted for body surface area (BSA) to account for individual differences [24]. BSA was calculated using the Mosteller formula (BSA = $\left.0.016667 \times W^{0.5} \times H^{0.5}\right)$. A higher OUES value (i.e., a steeper $\mathrm{VO}_{2} / \mathrm{VE}$ slope) indicates more efficient oxygen extraction from the cardiopulmonary system by the working skeletal muscles [3]. Because the OUES value is calculated as a regression slope, the unit is arbitrary. The OUES computation only included metabolic data collected during the GXT and excluded the warm up and recovery stages due to irregular ventilation that is often observed during those stages. We have previously shown excellent reliability (ICC $=.995, p<.001)$ between OUES values calculated at $75 \%, 90 \%$, and $100 \%$ of the exercise duration [19]. Therefore, we used the OUES values that sampled the entire exercise duration (100\%) as the primary CRF variable for the current study.

\section{Brain imaging acquisition}

MRI scanning was performed on a GE $\times 7503 \mathrm{~T}$ scanner (General Electric, Waukesha, WI, USA) with an eight-channel head coil and parallel imaging with the Array Spatial Sensitivity Encoding Technique. A T1-weighted volume scan was acquired in the axial plane with a 3D fast spoiled gradient-echo sequence using the following parameters: inversion time $(\mathrm{TI})=450 \mathrm{~ms}$; repetition time $(\mathrm{TR})=8.2 \mathrm{~ms}$; echo time $(\mathrm{TE})=3.2 \mathrm{~ms}$; flip angle $=12^{\circ}$; acquisition matrix $=256 \mathrm{~mm} \times 256 \mathrm{~mm}$, field of view $(\mathrm{FOV})=256 \mathrm{~mm}$; slice thickness $=1.0 \mathrm{~mm}$, no gap, yielding a voxel resolution of $1 \mathrm{~mm}$ isometric. A 3D T2 FLAIR sequence was acquired in the sagittal plane using the following parameters: $\mathrm{TI}=1868 \mathrm{~ms}$; $\mathrm{TR}=6000 \mathrm{~ms} ; \mathrm{TE}=123 \mathrm{~ms} ;$ flip angle $=90^{\circ}$; acquisition matrix $=256 \mathrm{~mm} \times 256 \mathrm{~mm}, \quad F O V=256 \mathrm{~mm}$; slice thickness $=2.0 \mathrm{~mm}$, no gap, yielding a voxel resolution of $1 \mathrm{~mm} \times 1 \mathrm{~mm} \times 2 \mathrm{~mm}$. Additional details have been previously described $[6,7]$.

\section{White matter hyperintensities segmentation}

The Lesion Segmentation Tool (LST) version 1.2.3 in SPM12 was used to calculate the total volume of WMH [43]. This toolbox is open source and uses automated segmentation with high reliability. For lesion segmentation, LST seeds lesions based on spatial and intensity probabilities from $\mathrm{T} 1$ images and hyperintense outliers on T2 FLAIR images. The intracranial volume (ICV) was calculated using the "reverse brain masking" method [30]. Total WMH was then divided by ICV and multiplied by 100 to obtain a measure of lesion-to-cranial 
volume in percent units $[6,7,43]$. This measure served as the dependent variable in all analyses and was log-transformed to normalize its distribution, as required by the assumptions for ordinary least squares regression [45].

\section{Statistical analysis}

Multiple linear regression was used to examine relationships between CRF, age, and WMH. We first fitted a model that investigated the relationship between age and WMH while controlling for APOE4, FH, body mass index, systolic blood pressure, and sex (Model 1). These covariates were applied to account for their contributions to interindividual variations in brain size, $\mathrm{WMH}$, and/or risk for $\mathrm{AD}[1,22,41,48]$.

Next, we refitted the original model while additionally including the OUES and age $\times$ OUES terms (Model 2). The OUES and age were centered at the mean of each variable. Where significant, the age $\times$ OUES term would indicate that the effect of age on WMH differs by CRF. A significant age $\times$ OUES interaction was further interrogated using simple main effects analyses. All analyses were conducted using IBM SPSS version 24. Statistical tests were considered significant at $p<.05$.

\section{Results}

Similar to the larger WRAP cohort, many participants in this sample had a positive $\mathrm{FH}(71 \%)$ and were APOE4 positive (43\%). The sample studied was $65.4 \%$ female. Other sample characteristics are presented in Table 1.

The results of Model 1 (see Table 2) revealed a strong positive association between age and WMH $(\beta(\mathrm{SE})=.01$ $(.003) ; t=3.89 ; p<.001)$. Sex was also a significant predictor of WMH $(\beta(\mathrm{SE})=-.082(.03) ; t=-2.71, p=.008)$, with men harboring less WMH burden compared to women. Of note, APOE4 was not a significant predictor of WMH $(\beta($ SE $)=-.015(.031) ; t=-0.50, p=.620)$. Similarly, $\mathrm{FH}$ was not a significant predictor of WMH $(\beta(\mathrm{SE})=.029$ (.034); $t=0.85, p=.396)$.

Model 2 (see Table 3) showed a significant interaction between age and CRF on WMH $(\beta(\mathrm{SE})=$ -.000024 (.0000096); $t=-2.47 ; p=.015)$. Per standard practice [12], we followed up on this interaction by conducting simple main effects analyses of the effect of age on WMH for Low OUES vs High OUES. To accomplish this, we set anchor points for Young vs Old and for Low OUES vs High OUES at one standard deviation below vs above the mean of each variable (see Table 1 for the respective values). As depicted in Fig. 1, these simple main effects analyses revealed that the effect of age on WMH accumulation remained significant in the Low OUES group ( $\beta(\mathrm{SE})$ $=.19(.043) ; t=4.41 ; p<.001)$ but not in the High OUES group $(\beta(\mathrm{SE})=.029(.047) ; t=0.62 ; p=.540)$.
Table 1 Background characteristics

\begin{tabular}{ll}
\hline Characteristic & Value \\
\hline Age (years) & $64.19(5.85)(49.58-74.96)$ \\
Female (\%) & 65.40 \\
Education (years) & $16.30(2.35)(12-22)$ \\
FH (\%) & 71 \\
APOE4 (\%) & 43 \\
MMSE & 29.37 (1.01) (24-30) \\
Hypertension (\%) & 14.0 \\
Diabetes (\%) & 1.8 \\
Smoker (\%) & 34.6 \\
Beta blocker usage (\%) & 6.5 \\
BMI (kg/m²) & $27.84(5.31)(17.65-48.03)$ \\
Systolic blood pressure (mmHg) & 123.72 (15.66) (94-162) \\
Diastolic blood pressure (mmHg) & $70.41(9.62)(44-90)$ \\
OUES & 1153.52 (290.72) (460-2290) \\
WMH (ml) & $2.90(5.23)(0.011-28.03)$ \\
ICV (ml) & $1466.46(140.65)(1175-1927)$ \\
Interval between MRI and GXT (years) & 1.04 (1.04) (0-4.42) \\
\hline
\end{tabular}

All values presented as mean (standard deviation) (range) unless noted otherwise

$F H$ family history of Alzheimer's disease, APOE4 apolipoprotein $\mathrm{E} \varepsilon 4$ allele carriage, MMSE Mini-Mental State Examination, BMI body mass index, OUES oxygen uptake efficiency slope, WMH white matter hyperintensities, ICV intracranial volume, MRI magnetic resonance imaging, GXT graded exercise testing

As noted earlier, our set of covariates (i.e., APOE4, FH, body mass index, systolic blood pressure) were selected based on prior evidence that they influence WMH and/ or AD risk. However, in this study, none of these covariates were significantly associated with WMH at the .05 threshold (all $p \geq .124$ ). Therefore, we repeated our analyses after excluding these covariates. Our original findings remained essentially unchanged. That is, there remained a positive association between age and WMH $(\beta(\mathrm{SE})=.01 \quad(.002) ; t=4.3223 ; p<.001)$ and there remained a significant interaction between CRF and age on $\mathrm{WMH} \quad(\beta(\mathrm{SE})=-.000025$ (.000009); $t=-2.62$;

Table 2 Association between age and WMH

\begin{tabular}{llll}
\hline Variable & $\beta($ SE) & $t$ & $p$ \\
\hline Age & $.01(.003)$ & 3.89 & $<.001$ \\
Sex & $-.082(.03)$ & -2.71 & .008 \\
SBP & $.001(.001)$ & 0.35 & .728 \\
FH & $.029(.034)$ & 0.85 & .396 \\
BMI & $-.001(.003)$ & -0.34 & .731 \\
APOE4 & $-.015(.031)$ & -0.50 & .620 \\
\hline
\end{tabular}

WMH white matter hyperintensities, SE standard error, SBP systolic blood pressure, $F H$ family history of Alzheimer's disease, $B M I$ body mass index, APOE 4 apolipoprotein E $\varepsilon 4$ allele carriage 
Table 3 CRF attenuates the effect of age on WMH

\begin{tabular}{llll}
\hline Variable & $\beta($ SE) & $t$ & $p$ \\
\hline Age & $.009(.003)$ & 3.48 & .001 \\
Sex & $-.073(.035)$ & -2.07 & .041 \\
SBP & $.000088(.001)$ & 0.091 & .928 \\
FH & $.027(.033)$ & 0.81 & .419 \\
BMI & $-.001(.003)$ & -0.50 & .619 \\
APOE4 & $-.011(.031)$ & -0.34 & .732 \\
OUES & $-.000043(.000063)$ & -0.68 & .495 \\
Age $\times$ OUES & $-.000024(.0000096)$ & -2.47 & .015
\end{tabular}

CRF cardiorespiratory fitness, $W M H$ white matter hyperintensities, SE standard error, $S B P$ systolic blood pressure, $F H$ family history of Alzheimer's disease, $B M I$ body mass index, APOE4 apolipoprotein E $\varepsilon 4$ allele carriage, OUES oxygen uptake efficiency slope

$p=.01)$. For completeness sake, we opted to retain the original model that included the covariates.

Furthermore, we ran additional analyses to investigate whether our primary findings were influenced by potential confounders such as vascular risk factors (e.g., hypertension, smoking, and diabetes), beta blocker usage, and physical activity (as measured by caloric expenditure on the CHAMPS questionnaire [44]). The relationship between age and WMH remained significant when further adjusted for these covariates $(\beta(\mathrm{SE})=.01(.003) ; t=3.23$; $p=.002)$. Similarly, the interaction between age and CRF on WMH also remained significant $(\beta(\mathrm{SE})=-.000022$ (.00001); $t=-2.22 ; p=.029)$. Accordingly, we opted to retain our original findings.

\section{Discussion}

In this study, we found that older age was associated with greater accumulation of WMH. Importantly, our results showed that aerobic fitness attenuates the relationship between age and WMH. For those with low aerobic fitness, there was a significant difference in white matter lesion volume between younger and older participants. However, for those with high CRF, a similar deleterious effect of age on the prevalence of white matter lesions was not observed.

A prior study from our group reported that advancing age predisposes individuals to an aggregation of $\mathrm{WMH}$, and that an increase in WMH is associated with decreased cognitive function [6]. Other groups have also found that WMH track with older age in the general population $[15,17,31,49]$. Our results mirror these past findings despite the fact that our cohort is relatively younger. Of interest, we present novel results showing that CRF moderates the relationship between age and WMH. Given that WMH contributes to the clinical manifestation of $\mathrm{AD}[8,16,33,40]$, CRF's curtailment of WMH accumulation raises the possibility that CRF may, thereby, slow progression toward the clinical syndrome of AD.

Previous reports have found significant relationships between CRF and $\mathrm{WMH}$ using $\mathrm{VO}_{2}$ peak as the index of CRF [11, 23, 50]. As discussed earlier, although deemed the gold standard for measuring CRF, true $\mathrm{VO}_{2}$ peak is often unattainable by older adults. Hence, various alternatives have been considered in the literature such as

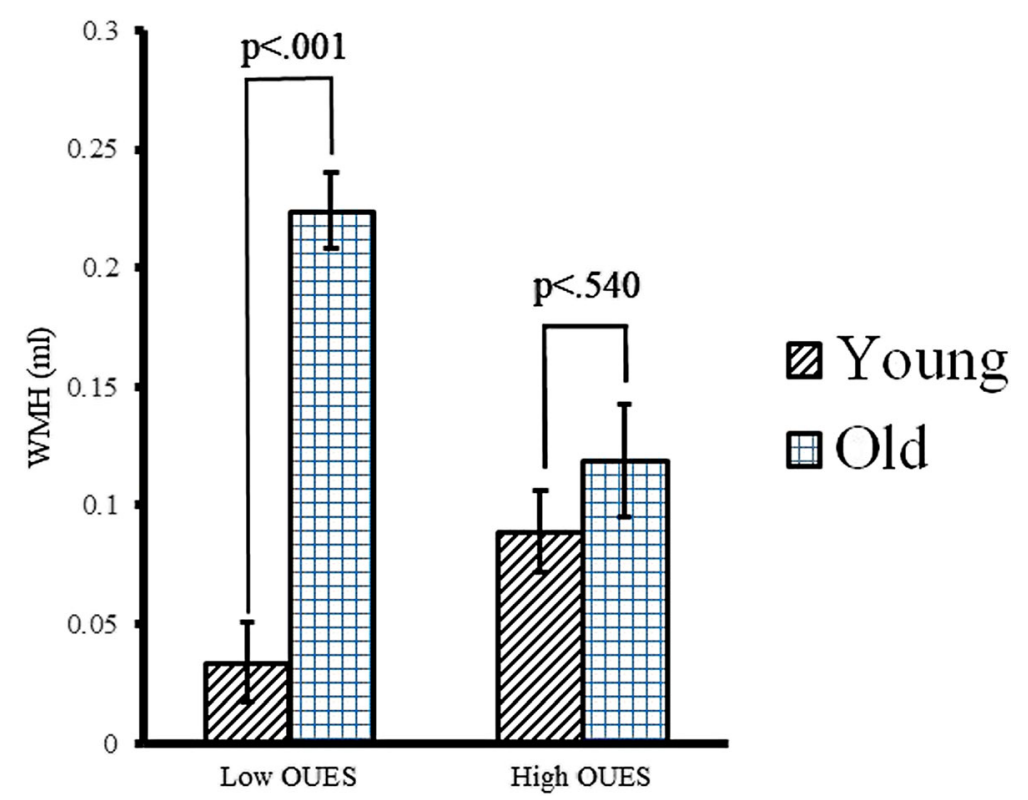

Fig. 1 Estimated WMH as a function of age and OUES. Although age and OUES were modeled as continuous variables in our analyses, to depict these simple main effects, Low OUES vs High OUES were set to one standard deviation below vs above mean OUES. Similarly, Young vs Old were set to one standard deviation below vs above mean age WMH white matter hyperintensities, OUES oxygen uptake efficiency slope 
non-GXT-based measures of CRF [7, 29] and OUES [3, 24]. Consistent with our recent publication [19], our present findings support the utility of the OUES as a viable metric for CRF in older adults, and highlight its sensitivity to important health outcomes such as cerebrovascular disease, brain aging, and risk for AD.

One possible mechanism for the results found in this study relates to cerebral perfusion. Previous studies in cognitively normal individuals have shown that an increase in WMH is associated with lower cerebral blood flow $[9,36]$. Also, higher cardiorespiratory fitness is associated with increased cerebral blood flow and better cognition in older adults $[9,26]$. Therefore, it is possible that higher cardiorespiratory fitness may protect against reductions in cerebral blood flow with advancing age, which then translates to a reduction in WMH. A formal test of this hypothesis will be the focus of future studies from our group.

This study is not without limitations. Neither APOE4 nor FH was significantly associated with WMH in our sample, even though other studies have previously reported such associations [5, 35]. Similarly, we did not assess relationships between WMH and $\beta$-amyloid or tau, the core pathological characteristics of $\mathrm{AD}$, as such an investigation was not the objective of this study. Accordingly, we cannot definitively say that interindividual variations in WMH in this sample are AD specific. Our design is cross-sectional in nature, which limits our ability to draw causal inferences. Future studies incorporating longitudinal observations would provide clearer insights into the evolution of WMH over time and how CRF affects that trajectory. Also, because the WRAP cohort is largely composed of highly educated, non-Hispanic white individuals harboring specific risk factors for $\mathrm{AD}$, there is a potential restriction of the generalizability of our results to the larger population. Relatedly, WRAP participants who volunteer for additional ancillary studies might differ in unmeasured ways from those who do not (e.g., our study sample was slightly older (mean age 64.19 years) than the larger WRAP cohort (mean age 62.89 years)). Lastly, we did not have information about the physical fitness of the participants earlier in their life, so we cannot determine how that may affect their current physical fitness or our outcomes of interest.

\section{Conclusion}

We found that in a small sample at risk for AD, advancing age was associated with an accumulation of WMH. However, higher CRF attenuated this adverse impact of age on WMH. These findings contribute to the larger body of evidence highlighting the potential benefits of a physically active lifestyle, specifically as relates to improved cerebrovascular health and healthier brain aging.

\section{Acknowledgements}

Special thanks to the researchers and staff at the Waisman Center, University of Wisconsin-Madison, where the brain scans took place, and to participants in the Wisconsin Registry for Alzheimer's Prevention for their continued dedication.

\section{Funding}

This work was supported by National Institute on Aging grants K23 AG045957 (OCO), R21 AG051858 (OCO), R01 AG037639 (BBB), R01 AG027161 (SCJ), R01 AG021155 (SCJ), and P50 AG033514 (SA); and by a Clinical and Translational Science Award (UL1RR025011) to the University of Wisconsin, Madison. Portions of this research were supported by the Extendicare Foundation, Alzheimer's Association, Wisconsin Alumni Research Foundation, the Helen Bader Foundation, Northwestern Mutual Foundation, and from the Veterans Administration including facilities and resources at the Geriatric Research Education and Clinical Center of the William S. Middleton Memorial Veterans Hospital, Madison, WI, USA.

\section{Availability of data and materials}

The corresponding author has full access to all the data reported in this study and takes responsibility for the integrity of the data and the accuracy of the data analyses.

\section{Authors' contributions}

Study design, drafting of manuscript, and statistical analysis were done by CJV and OCO. Acquisition, analysis, and interpretation of data and critical revision of the manuscript was done by CJV, VP, RJD, LLL, EB, JMO, CLG, CMC, HAR, YM, $\mathrm{BBB}, \mathrm{SA}, \mathrm{MAS}, \mathrm{BPH}, \mathrm{SC}, \mathrm{DBC}$, and OCO. Funding was obtained by BBB, SCJ, SA, and OCO. All authors read and approved the final manuscript.

\section{Ethics approval and consent to participate}

All study procedures were approved by the University of Wisconsin Institutional Review Board and each subject provided signed informed consent before participation.

\section{Consent for publication}

Not applicable.

\section{Competing interests}

The data described in this manuscript have not been published in any prior reports and are not presently under consideration for possible publication by another journal. The authors do not have any conflicts of interest to report pertaining to this manuscript.

\section{Publisher's Note}

Springer Nature remains neutral with regard to jurisdictional claims in published maps and institutional affiliations.

\section{Author details}

${ }^{1}$ Geriatric Research Education and Clinical Center, William S. Middleton Memorial Veterans Hospital, Madison, WI 53705, USA. 'Wisconsin Alzheimer's Disease Research Center, University of Wisconsin School of Medicine and Public Health, Madison, WI 53792, USA. 'Wisconsin Alzheimer's Institute, University of Wisconsin School of Medicine and Public Health, Madison, WI 53705, USA. ${ }^{4}$ Department of Kinesiology, University of Wisconsin School of Education, Madison, WI 53792, USA. ${ }^{5}$ Department of Neurology, University of Wisconsin School of Medicine and Public Health, Madison, WI 53705, USA. ${ }^{6}$ Research Service, William S. Middleton Memorial Veterans Hospital, Madison, WI 53705, USA. ${ }^{7}$ Department of Radiology, University of Wisconsin School of Medicine and Public Health, Madison, WI 53705, USA. ${ }^{8}$ Department of Psychology, University of Illinois-Chicago, Chicago, IL 60607, USA. ${ }^{9}$ Rush Alzheimer's Disease Center, Rush University Medical Center, Chicago, IL 60612, USA. ${ }^{10}$ Department of Medicine and Alzheimer's Disease Research Center, University of Wisconsin School of Medicine and Public Health, Madison, WI 53792, USA.

Received: 19 March 2018 Accepted: 6 September 2018 Published online: 24 September 2018

\section{References}

1. Alzheimer's Association. 2016 Alzheimer's Disease Facts and Figures. 2016 Retrieved from http://www.alz.org/facts/ 
2. American College of Sports Medicine, Pescatello LS. ACSM's guidelines for exercise testing and prescription. 9th ed. Philadelphia: Wolters Kluwer/ Lippincott Williams \& Wilkins Health; 2014.

3. Baba R, Nagashima M, Goto M, Nagano Y, Yokota M, Tauchi N, Nishibata K. Oxygen uptake efficiency slope: a new index of cardiorespiratory functional reserve derived from the relation between oxygen uptake and minute ventilation during incremental exercise. J Am Coll Cardiol. 1996;28(6):1567-72.

4. Balke B, Ware RW. An experimental study of physical fitness of Air Force personnel. U S Armed Forces Med J. 1959;10(6):675-88.

5. Bendlin BB, Ries ML, Canu E, Sodhi A, Lazar M, Alexander AL, et al. White matter is altered with parental family history of Alzheimer's disease. Alzheimers Dement. 2010;6(5):394-403. https://doi.org/10.1016/j.jalz.2009.11.003.

6. Birdsill AC, Koscik RL, Jonaitis EM, Johnson SC, Okonkwo OC, Hermann BP, et al. Regional white matter hyperintensities: aging, Alzheimer's disease risk, and cognitive function. Neurobiol Aging. 2014;35(4):769-76. https://doi.org/ 10.1016/j.neurobiolaging.2013.10.072.

7. Boots EA, Schultz SA, Oh JM, Larson J, Edwards D, Cook D, et al, Cardiorespiratory fitness is associated with brain structure, cognition, and mood in a middle-aged cohort at risk for Alzheimer's disease. Brain Imaging Behav. 2015;9(3):639-49. https://doi.org/10.1007/s11682-014-9325-9.

8. Brickman AM, Provenzano FA, Muraskin J, Manly JJ, Blum S, Apa Z, et al. Regional white matter hyperintensity volume, not hippocampal atrophy, predicts incident Alzheimer disease in the community. Arch Neurol. 2012; 69(12):1621-7. https://doi.org/10.1001/archneurol.2012.1527.

9. Brickman AM, Zahra A, Muraskin J, Steffener J, Holland CM, Habeck C, et al. Reduction in cerebral blood flow in areas appearing as white matter hyperintensities on magnetic resonance imaging. Psychiatry Res. 2009; 172(2):117-20. https://doi.org/10.1016/j.pscychresns.2008.11.006.

10. Brown $A D$, McMorris CA, Longman RS, Leigh R, Hill MD, Friedenreich CM, Poulin MJ. Effects of cardiorespiratory fitness and cerebral blood flow on cognitive outcomes in older women. Neurobiol Aging. 2010;31(12):2047-57. https://doi.org/10.1016/.neurobiolaging.2008.11.002.

11. Burzynska AZ, Chaddock-Heyman L, Voss MW, Wong CN, Gothe NP, Olson EA, et al. Physical activity and cardiorespiratory fitness are beneficial for white matter in low-fit older adults. PLoS One. 2014;9(9):e107413. https:// doi.org/10.1371/journal.pone.0107413.

12. Cohen J, Cohen P, West SG, Aiken LS. Applied multiple regression/ correlation analysis for behavioral sciences. 3rd ed. Mahwah: Lawrence Erlbaum Associates Publishers; 2003

13. Colcombe SJ, Erickson KI, Raz N, Webb AG, Cohen NJ, McAuley E, Kramer AF. Aerobic fitness reduces brain tissue loss in aging humans. J Gerontol A Biol Sci Med Sci. 2003;58(2):176-80.

14. de Bruijn RF, Schrijvers EM, de Groot KA, Witteman JC, Hofman A, Franco $\mathrm{OH}$, et al. The association between physical activity and dementia in an elderly population: the Rotterdam Study. Eur J Epidemiol. 2013;28(3):277-83. https://doi.org/10.1007/s10654-013-9773-3.

15. de Leeuw FE, de Groot JC, Achten E, Oudkerk M, Ramos LM, Heijboer R et al. Prevalence of cerebral white matter lesions in elderly people: a population based magnetic resonance imaging study. The Rotterdam Scan Study. J Neurol Neurosurg Psychiatry. 2001;70(1):9-14.

16. Debette $\mathrm{S}$, Markus HS. The clinical importance of white matter hyperintensities on brain magnetic resonance imaging: systematic review and meta-analysis. BMJ. 2010;341:c3666. https://doi.org/10.1136/bmj.c3666.

17. DeCarli C, Massaro J, Harvey D, Hald J, Tullberg M, Au R, et al. Measures of brain morphology and infarction in the framingham heart study: establishing what is normal. Neurobiol Aging. 2005;26(4):491-510. https:// doi.org/10.1016/j.neurobiolaging.2004.05.004.

18. Defina LF, Willis BL, Radford NB, Gao A, Leonard D, Haskell WL, et al. The association between midlife cardiorespiratory fitness levels and later-life dementia: a cohort study. Ann Intern Med. 2013;158(3):162-8. https://doi. org/10.7326/0003-4819-158-3-201302050-00005.

19. Dougherty RJ, Lindheimer JB, Stegner AJ, Van Riper S, Okonkwo OC, Cook DB. An objective method to accurately measure cardiorespiratory fitness in older adults who cannot satisfy widely used oxygen consumption criteria. J Alzheimers Dis. 2018;61 (2):601-11.

20. Dougherty RJ, Schultz SA, Boots EA, Ellingson LD, Meyer JD, Van Riper S, et al. Relationships between cardiorespiratory fitness, hippocampal volume, and episodic memory in a population at risk for Alzheimer's disease. Brain Behav. 2017;7(3):e00625. https://doi.org/10.1002/brb3.625.

21. Gordon BA, Rykhlevskaia El, Brumback CR, Lee Y, Elavsky S, Konopack JF, et al. Neuroanatomical correlates of aging, cardiopulmonary fitness level, and education. Psychophysiology. 2008;45(5):825-38. https://doi.org/10. 1111/j.1469-8986.2008.00676.x.

22. Gottesman RF, Coresh J, Catellier DJ, Sharrett AR, Rose KM, Coker LH, et al. Blood pressure and white-matter disease progression in a biethnic cohort Atherosclerosis Risk in Communities (ARIC) study. Stroke. 2010;41(1):3-8. https://doi.org/10.1161/STROKEAHA.109.566992.

23. Hayes SM, Salat DH, Forman DE, Sperling RA, Verfaellie M. Cardiorespiratory fitness is associated with white matter integrity in aging. Ann Clin Transl Neurol. 2015;2(6):688-98. https://doi.org/10.1002/acn3.204.

24. Hollenberg M, Tager IB. Oxygen uptake efficiency slope: an index of exercise performance and cardiopulmonary reserve requiring only submaximal exercise. J Am Coll Cardiol. 2000;36(1):194-201.

25. Honea RA, Thomas GP, Harsha A, Anderson HS, Donnelly JE, Brooks WM, Burns JM. Cardiorespiratory fitness and preserved medial temporal lobe volume in Alzheimer disease. Alzheimer Dis Assoc Disord. 2009;23(3):188-97. https://doi.org/10.1097/WAD.0b013e31819cb8a2

26. Johnson NF, Gold BT, Bailey AL, Clasey JL, Hakun JG, White M, et al. Cardiorespiratory fitness modifies the relationship between myocardial function and cerebral blood flow in older adults. Neuroimage. 2016;131: 126-32. https://doi.org/10.1016/j.neuroimage.2015.05.063.

27. Johnson NF, Kim C, Clasey JL, Bailey A, Gold BT. Cardiorespiratory fitness is positively correlated with cerebral white matter integrity in healthy seniors. Neuroimage. 2012;59(2):1514-23. https://doi.org/10.1016/j. neuroimage.2011.08.032.

28. Johnson SC, Koscik RL, Jonaitis EM, Clark LR, Mueller KD, Berman SE, et al. The Wisconsin Registry for Alzheimer's Prevention: a review of findings and current directions. Alzheimers Dement (Amst). 2018;10:130-42. https://doi. org/10.1016/j.dadm.2017.11.007.

29. Jurca R, Jackson AS, LaMonte MJ, Morrow JR Jr, Blair SN, Wareham NJ, et al. Assessing cardiorespiratory fitness without performing exercise testing. Am J Prev Med. 2005;29(3):185-93. https://doi.org/10.1016/j.amepre.2005.06.004.

30. Keihaninejad S, Heckemann RA, Fagiolo G, Symms MR, Hajnal JV, Hammers A, Alzheimer's Disease Neuroimaging, I. A robust method to estimate the intracranial volume across MRI field strengths (1.5T and 3T). Neuroimage. 2010;50(4):1427-37. https://doi.org/10.1016/..neuroimage.2010.01.064.

31. King KS, Peshock RM, Rossetti HC, McColl RW, Ayers CR, Hulsey KM, Das SR. Effect of normal aging versus hypertension, abnormal body mass index, and diabetes mellitus on white matter hyperintensity volume. Stroke. 2014:45(1): 255-7. https://doi.org/10.1161/STROKEAHA.113.003602.

32. Koscik RL, La Rue A, Jonaitis EM, Okonkwo OC, Johnson SC, Bendlin BB, et al. Emergence of mild cognitive impairment in late middle-aged adults in the wisconsin registry for Alzheimer's prevention. Dement Geriatr Cogn Disord. 2014;38(1-2):16-30. https://doi.org/10.1159/000355682.

33. Lee, S., Viqar, F., Zimmerman, M. E., Narkhede, A., Tosto, G., Benzinger, T. L., ... Dominantly Inherited Alzheimer, N. White matter hyperintensities are a core feature of Alzheimer's disease: evidence from the dominantly inherited Alzheimer network. Ann Neurol, 2016 79(6), 929-939. doi:https://doi.org/10. 1002/ana.24647.

34. Liao D, Cooper L, Cai J, Toole JF, Bryan NR, Hutchinson RG, Tyroler HA. Presence and severity of cerebral white matter lesions and hypertension, its treatment, and its control. The ARIC Study. Atherosclerosis Risk in Communities Study. Stroke. 1996;27(12):2262-70.

35. Lunetta, K. L., Erlich, P. M., Cuenco, K. T., Cupples, L. A., Green, R. C., Farrer, L. A., ... Group, M. S. Heritability of magnetic resonance imaging (MRI) traits in Alzheimer disease cases and their siblings in the MIRAGE study. Alzheimer Dis Assoc Disord, 2007 21(2), 85-91. doi:https://doi.org/10.1097/WAD. Ob013e3180653bf7.

36. Marstrand JR, Garde E, Rostrup E, Ring P, Rosenbaum S, Mortensen EL, Larsson HB. Cerebral perfusion and cerebrovascular reactivity are reduced in white matter hyperintensities. Stroke. 2002;33(4):972-6.

37. Perea RD, Vidoni ED, Morris JK, Graves RS, Burns JM, Honea RA. Cardiorespiratory fitness and white matter integrity in Alzheimer's disease. Brain Imaging Behav. 2016;10(3):660-8. https://doi.org/10.1007/s11682-015-9431-3.

38. Prakash RS, Voss MW, Erickson KI, Lewis JM, Chaddock L, Malkowski E, et al. Cardiorespiratory fitness and attentional control in the aging brain. Front Hum Neurosci. 2011;4:229. https://doi.org/10.3389/fnhum.2010.00229.

39. Prins ND, Scheltens $P$. White matter hyperintensities, cognitive impairment and dementia: an update. Nat Rev Neurol. 2015;11(3):157-65. https://doi. org/10.1038/nrneurol.2015.10

40. Provenzano, F. A., Muraskin, J., Tosto, G., Narkhede, A., Wasserman, B. T., Griffith, E. Y., ... Alzheimer's Disease Neuroimaging, I. White matter 
hyperintensities and cerebral amyloidosis: necessary and sufficient for clinical expression of Alzheimer disease? JAMA Neurol,2013 70(4), 455-461. doi:https://doi.org/10.1001/jamaneurol.2013.1321.

41. Ruigrok AN, Salimi-Khorshidi G, Lai MC, Baron-Cohen S, Lombardo MV, Tait RJ, Suckling J. A meta-analysis of sex differences in human brain structure. Neurosci Biobehav Rev. 2014;39:34-50. https://doi.org/10.1016/j.neubiorev. 2013.12.004.

42. Sager MA, Hermann B, La Rue A. Middle-aged children of persons with Alzheimer's disease: APOE genotypes and cognitive function in the Wisconsin Registry for Alzheimer's Prevention. J Geriatr Psychiatry Neurol. 2005;18(4):245-9. https://doi.org/10.1177/0891988705281882.

43. Schmidt P, Gaser C, Arsic M, Buck D, Forschler A, Berthele A, et al. An automated tool for detection of FLAIR-hyperintense white-matter lesions in multiple sclerosis. Neuroimage. 2012;59(4):3774-83. https://doi.org/10.1016/j. neuroimage.2011.11.032

44. Stewart AL, Mills KM, King AC, Haskell WL, Gillis D, Ritter PL. CHAMPS physical activity questionnaire for older adults: outcomes for interventions. Med Sci Sports Exerc. 2001;33(7):1126-41.

45. Tabachnick BG, Fidell LS. Using multivariate statistics. 5th ed. Boston: Pearson/Allyn \& Bacon; 2007.

46. Vidoni ED, Honea RA, Billinger SA, Swerdlow RH, Burns JM. Cardiorespiratory fitness is associated with atrophy in Alzheimer's and aging over 2 years. Neurobiol Aging. 2012;33(8):1624-32. https://doi.org/10.1016/j. neurobiolaging.2011.03.016.

47. Wardlaw, J. M., Smith, E. E., Biessels, G. J., Cordonnier, C., Fazekas, F., Frayne, R., ... nE uroimaging, S. T. f. R. V. C. o. Neuroimaging standards for research into small vessel disease and its contribution to ageing and neurodegeneration Lancet Neurol, 2013 12(8), 822-838. doi:https://doi.org/ 10.1016/S1474-4422(13)70124-8

48. Windham BG, Lirette ST, Fornage M, Benjamin EJ, Parker KG, Turner ST, et al, Associations of brain structure with adiposity and changes in adiposity in a middle-aged and older biracial population. J Gerontol A Biol Sci Med Sci. 2017;72(6):825-31. https://doi.org/10.1093/gerona/glw239.

49. Yoshita M, Fletcher E, Harvey D, Ortega M, Martinez O, Mungas DM, et al. Extent and distribution of white matter hyperintensities in normal aging, MCl, and AD. Neurology. 2006;67(12):2192-8. https://doi.org/10.1212/01.wnl. 0000249119.95747.1f.

50. Zhu N, Jacobs DR Jr, Schreiner PJ, Launer LJ, Whitmer RA, Sidney S, et al. Cardiorespiratory fitness and brain volume and white matter integrity: The CARDIA Study. Neurology. 2015;84(23):2347-53. https://doi.org/10.1212/ WNL.0000000000001658

Ready to submit your research? Choose BMC and benefit from:

- fast, convenient online submission

- thorough peer review by experienced researchers in your field

- rapid publication on acceptance

- support for research data, including large and complex data types

- gold Open Access which fosters wider collaboration and increased citations

- maximum visibility for your research: over $100 \mathrm{M}$ website views per year

At $\mathrm{BMC}$, research is always in progress.

Learn more biomedcentral.com/submissions 